\title{
The Nexus Between Religious Practices and Rural Community Development in Ethiopia: The Study of Ethiopian Orthodox Church Monasteries Experience
}

\author{
MENBERU BEKABIL WORKNEH* ALEMAYEHU MULAT LIYEW \\ Department of Sociology, Debre Markos University, Debre Markos Ethiopia
}

\begin{abstract}
People argue that religion hinders socio economic development confined to non working saint days while there are a number of works being done in these days that are equivalent to "working" days. The overall objective of this study is to examine the role of religious practices to rural community development with a particular reference to Ethiopian Orthodox Church Monasteries, particularly Sellasie Monastery of Debre Elias Woreda, East Gojjam Zone, Amhara Region. A cross-sectional study design and qualitative research approach was used emphasizing on a phenomological methodology. Hence, in-depth interviews, Key informant interview, Focus Group Discussions and Field observation have been used to collect primary data. Study participants were selected from ascetic members, services users and surrounding community residents of the study monastery by using purposive sampling. The major finding indicates that hard work is considered as healing and rehabilitation mechanism and activities being undertaken in the study monastery have an influence on livelihoods, social attachments and psycho-social conditions of the communities. Attendants in the monastery and surrounding rural communities have being educated and baptized to be well and productive members. Moreover, the monastery has established practical income generating activities for residents of both monastic and surrounding community farmers. In general, the religious practices in the study area have been playing great role in the reduction of poverty and harmful traditional practices (including criminal acts), and for the improvement of health, community mobilization, social solidarity and therefore economic development of surrounding rural communities.
\end{abstract}

Keywords: Religion, religious practice, Monastery, Community development

DOI: $10.7176 / \mathrm{JCSD} / 60-03$

Publication date: June $30^{\text {th }} 2020$

\section{Introduction}

To some, religion affects social and economic progress by making people dogmatic and superstitious which results in an opposition to scientific discoveries and technological advancements. Religion also encourages exploitation (casting people who are not member of a certain religion), and creates intolerance, mistrust, hatred and jealousy among people (Wolfe and Moorhead 2015). To some others, it satisfies the social, psychological, spiritual, and material needs that bring social welfare and cohesion, acts as an agency of social control and socialization, establishes solidarity, provides peace of mind and influences economic life (World Values Survey 2014; Andrews 2011).

Though all religions do not have quite similar essence on the issue of development, Ruben (2011) claims that religion plays its own role in supporting development by serving as an interactive force between ethical and material forces. Borowik, Dinka and Sinisa (2004) also argues that there is a characteristic compatibility between religious institutions and social structures at any stages of socio-economic development and asserted that considering religion as an irrelevant or as a mere ideological indoctrination is a strategy which is likely to jeopardize development efforts.

Previous studies by Zaidi (2010), Alonso (2015), Philipo (2014) and Rahmany (2006), describe the close and direct relation between religious practices (including FBOs) and development in Pakistan, Nigeria, Tanzania and Saudi Arabia respectively. The study by Zaidi (2010), reveals that Muslim FBOs have a close relationship with both other non-governmental and governmental organizations in several service related programs focusing on health and education. Moreover, in Nigeria, the potential of culture, religion, and traditional knowledge on food and nutrition security by concentrating on food preparation, processing, safety and the impact of dietary change accompanied by dietary rules of the respective culture, religion and tradition on members of the community (Alonso, 2015).

In Ethiopia, Kumilachew (2015), and Alemayehu (2007) have tried to investigate the relation between religion and development in the country. For example, Kumilachew (2015), in his study of "The Socioeconomic Roles of Ethiopian Orthodox Tewahido Churches in Addis Ababa"' stated that religiosity in orthodox Christians results development in such a way that religious services and occupations foster community development. Alemayehu (2007) also explains the woody vegetation of church forests could provide an opportunity for preservation and/or restoration of diversified plants in the country.

However, these studies were limited to urban areas where no many holydays have been observed because of 
type of occupation and modern effect and the roles of Orthodox Church for forest preservation. Hence, this study is unique focusing on the role of religious practice in rural community development from the experience of monastic sites where Ethiopian Orthodox Church is blamed for effecting excessive holidays and festivities followed by prohibitive regulations on work. Moreover, livelihood assets and strategies being used by the study monastery to surrounding community, which were not previously studied have also been given due consideration in this study. Therefore, this study has been conducted in Sellassie monastery of Debre Elias Woreda where religious practices have been contributing specific to the respective rural communities' development.

\section{Study setting and research methodology Description of the Study Area}

Sellassie Monastery is found in Debre Elias district of eastern Gojjam zone in Amhara National Regional State. It is located $379 \mathrm{~km}$ from Addis Ababa, $349 \mathrm{~km}$ from Bahir Dar (the region's capital), $80 \mathrm{~km}$ from Debre Markos City,(zonal capital) and $38 \mathrm{~km}$ in the western direction from district town), and It has been founded in January 1994 E.C. by five monks (Debre Elias District Culture and Tourism Office 2014). This monastery is selected because its hard working principle as a healing from health and sin, rehabilitation and production mechanism of its member and surrounding community differs the monastery from other Ethiopian Orthodox Church monasteries.

\section{Demographic Composition of the Monastery}

For about 83 ascetic people constantly reside in the monastery of which 59 are nuns and the rest 24 are monks. Moreover, for temporary purpose, quite a number of people visit the monastery mostly to get different services from the monastic community. In fact, people, who are continuously in-and-out of the monastery, cannot be exactly known because they can, either, be increased or decreased in different times. However, on average, about 250-300 persons join the monastery per day for temporary purpose, whose existence depend on the achievement of the needed services from the monastery, and, at the same time, equivalent number of persons leave the monastery within a day. But at the time of annual Saint Days being celebrated in the monastery, on average, about 15,00018,000 believers attend the festivity. At this time, board and lodging of these people is covered by the monastery for free.

\section{Research Methods}

This study aimed at investigating whether religious institutions have a role in rural community development taking both the insider (monastic community members) and outsiders' point of view of the study participants. To this end, a phenomenological methodology of qualitative research approach with a cross sectional study design was employed. Data were gathered by using in depth interview, focus group discussion, key informant interview, and filed observation to gather rich, multiple and important data from the respondents.

\section{Sampling Design and Procedure}

In this study, study participants were selected by using purposive sampling. Purposive sampling is important to have study participants that will yield the most relevant and plentiful data in the issue to be studied (Yin 2011). Therefore, in order to get rich and full information in relation to religious (monastic) institutions with their respective role to rural community development; and by taking religious perspectives on development into consideration, key informants among founders of the study monastery and associated leaders (monks) were, initially, selected purposively. Moreover, people, who are familiar with the monastery; either by using different services of the monastery (such as holy water) or who have the experience of participating in different activities of the monastery were selected as sample study participants. In the same fashion participants from the surrounding rural community were purposively based on their experience to the monastery and they were affected (either positively or negatively) by the very existence of the monastery. This is important to get their view towards the overall activities of the monastic community. Besides, participants, whose lives had been greatly influenced due to activities practiced in the monastery, have also been selected from elsewhere but found in the monastery at the time of data collection. Having this procedure, numbers of sample study participants were determined based on the saturation of the information (data) collected as long as the issues of religious practices, in relation with rural community development, are concerned. Accordingly, five in depth interview, three key informant interviews and three focus group discussions have been conducted with respective participants. Direct observation was also done as well.

\section{Method of Data Analysis and Interpretation}

Data gained from all qualitative methods of data collection were thematically analyzed. Initially, the collected data were reviewed through reading of the note taken and listening the tape records. The tape recorded data were directly transcribed into Amharic-local language and, then, translated into English. Then, the data was organized by using different codes in accordance with the respective themes. Finally, the data were presented and interpreted 
in line with the objective of the research. In data presentation, direct quoting was also used to make a comprehensive understanding of lived experience of respondents and to make sure the reliability of the data. Moreover, data organization, presentation and interpretation were checked based on themes of the data collection tools to assure the validity of the data.

\section{Ethical Considerations}

In conducting research, considering ethical issue into account is very important. In this study, all concerned bodies at all levels were informed about the purpose and the advantage of this study. Written consents and assent were requested from respondents and admintrators before the interview started. Accordingly, the researchers obtained permission from respondents and the respective concerned bodies of the monastery and district. Moreover, researchers had been acknowledging participants values, norms and regulations and keeping their confidentiality in the whole process of carrying out this study.

\section{Findings}

\section{The Role of the Monastery to Surrounding Rural Communities' Development}

Religious activities taking place within the monastery are not limited on mere preaching of fasting, prayer and baptism through holy water to be healed and get eternal life. The monastic community, through its various faith driven developmental activities, mostly with its different agro forestry practices, is playing its own role for surrounding communities' development.

\section{Infrastructure development}

The place where Sellassie Monastery located is far from the nearby town. This made different agricultural products difficult to transport to the market. Cognizant of this problem, Sellassie monastery got about 16 k.m gravel road to be constructed from the monastery and surrounding area to nearby town in collaboration with regional road authority.

As the discussant explained, the construction of the road created various opportunities not only to residents of the study monastic community but also to neighboring community. It was impossible for the road to be constructed by the community. The monastery sponsored 8 million birr for the construction of this road. After the construction of the road, different agricultural products of the monastery and surrounding communities are being easily transported to the market.

We used to walk 5-6 hours on foot from the village to the nearby town for selling our products. But now, since the gravel road is constructed by the help of sellassie monastery, we travel below an hour either by car or motor bicycle that help us save our time and energy (Focus group discussion, march, 2017)

\section{Creating Income Generating Activities to the Nearby Community Members}

Sellassie Monastery is creating quite a number of job opportunities to different members of surrounding communities, especially youth and the poor. The response from the Abeminet (head of the monastry) and participants from the community shows that the youth especially from poor families are benefited income generating activities created by the monastery. Theses youth have been trained and given different agricultural products (vegetables and fruits sugarcane, banana, Mango etc ) from the monastery for loan to make their money (from profit) by selling in the near market and pay back only the cost of the production process to the monastery. Below, 28 years old farmer from the community whom the researchers found collecting fruits from the monastery expressed:

I had not been doing anything since my parents gave me nothing for my livelihood. Now I am collecting banana \& sugarcane to sell for profit. I will sell the sugarcane for 5 birr per 1 meter, but I will pay back to the monastery 1 birr per 1 mentor. This means I will have 4 birr profit from 1 meter sugar cane. So, I am now happy, thanks to Selassie (the monastery) I have job, I am able to support myself and my family too. (In-depth interview with 2, march, 2017).

Similarly, FGD discussants explained that, though the monastery is perceived as established for preaching and baptizing purpose, various opportunities are created to most of the community. Surrounding farmers have been benefited sharing its irrigation based agricultural productivity to be sold for profit. Besides, they discussed, in this way, the monastery is helping about 12 children who have lost one or both of their parents.

The discussant also stated that the monastery gives initial capital for small non agricultural activities. Three women associations have been benefited from this package. They are making money preparing and selling local drinks such as, tella, tea, and food.

\section{Giving Psycho Social Support}

Religious practices taking place in the study monastery have their own positive effects on the conscience relief, psychological strength and, more importantly, to an individual's overall relation with others. Respondents 
explained that in Sellasie monastery, no matter how different in their color, race, background, and where they come from, people who are constantly and/or temporarily present in the monastery have full equality at any time of their existence in the study monastery, without any favor of one against another since the core values and beliefs of EOTC request to do so. People work together, pray together, and this get them feel togetherness, sense of belongingness and to be stable, happy courage for hard working.

A 46 years old religious leader (Afememhir), who has a responsibility of working as a public relation officer in the monastery, also described the way members of the monastic community are received and treated as follows:

God teaches us not to make differences among people. Hence we welcome people with good respect and we assign tasks equally. We also give our community psychosocial counseling services based on biblical perspectives. This is to keep their wellness, by this to get them productive citizens (key informant interview, march 2017).

This is supported by the responses from FGD discussants in the monastic community members who are constantly living in the monastery. They indicated that, there are certain special services being delivered in the monastery. (1) people are given counseling services by religious leaders or monks to be relieved from psychological problems, anxiety and stress. (2) beyond psychological problems, people are also facing other health defects and are being healed from their health problems by being baptized through the holy water or "Tsebel" of the monastery.

\section{Healing Through Holy Water (Tsebel)}

Among the respondents found in the monastery volunteerism, a 19 year girl, who is $11^{\text {th }}$ grade student was describing health problems she faced and how she healed by holy water of the monastery as follows:

I had a disease of mental disorder that frequently caused me to drop out of school. I had been seeing different physicians, but not healed. Now here I baptized by holy water for 21 days. Many thanks to the Lord, $i$ am now very well and stable. Now I am able to be back to school soon. (In-depth interview, march 2017).

We can understand from the above cases, religious practices healing by holy water by the holy water (tsebel), have an equivalent value to modern types of medicines. The following case of participant (a 37 years old farmer) can also strengthen the above argument.

Beginning from 2003 E.C. my legs were half paralyzed and as a result, I used to walk through walking stick. I heard the effect of this monastery in healing by holywater. Then I come to this monastery and got baptized, I was praying with monks. Now you can see I am very well, able to walk very well! (In-depth interview, march 2017).

From the above explanation, one can realize that, the religious practices in the monastery have been helping people to be healed physical pathologies, relived from different psycho-social problem and get them be productive community members.

\section{Getting people Disciplined and Conformist (Crime Prevention in Nearby Communities)}

Before the establishment of the Sellassie monastery, the area (especially surrounding the monastery), were known for its high level of crime that had been frequently committed.

As key informant, an expert, aged 36 from the district community policing office described that, there were frequent thefts, murders and other physical attacks in the area. But now, those types of criminal activities are significantly decreasing as a result of the unreserved effort of religious leaders and monks of sellassie monastery by giving essential biblical preaching, counseling for the surrounding community about the devil of crime for human beings.

The monastic administration is also helping different youth, particularly who are from surrounding communities, to be disciplined through preaching, counseling and arranging income generating activities for them. It provides for the youth with its agricultural products for free till they become able to make an initial capital.

\section{Conclusion}

As of Pesonen and Vesala 2006, in rural societies, the activities being carried out by religious congregations have a multifaceted importance from mental and spiritual support, meant for all members of the church, to more economic support for the poorest.

Similar to this, the study finding in sellassie monastery shows that, rather than hindering social and economic progress by making people superstitious and having extra holidays( Wolfe and Moorhead 2015) the religious practices in the study monastery have a considerable effect to the overall development of its associated residents, neighboring rural communities, and some other people who are going there from elsewhere by building good work habit, proving their livelihood asset as well as social attachment.

In the study monastry, there are different religious practices carried out by monks and religious leaders. These are group prayer, religious based counseling services to relive people from different psycho social problems; 
healing with holy water (Tsebel); And there are also religiously institutionalized activities expected to be practiced by the residents, surrounding community members frequently visiting the monastery- voluntarily engaging in different types of works for blessing (yebereket sira) and even as a way of getting disciplined. These and other religious practices in the monastery have been getting the rural communities in and outside to be disciplined, healthy and productive members of the society.

In addition, in this monastery it is believed that, remaining idle counting all things to the holidays exposes them for sinful thought and acts such as adultery, murder, theft and other crimes. Accordingly, getting oneself busy with hard working is sub culture of the monastery as it considered as a way through which sanctification from God is given and sin is expiated.

Moreover, the monastery is playing great role by improving the livelihood of the surrounding rural community. The farmers are benefited from various economic opportunities created by the monastery. They take its irrigation based agricultural products for fewer prices (set by the monastery), sell for profit and pay back to the church the less amounts. The monastery also empowers the rural women helping them to engage in income generating activities by providing with initial capital for small non agricultural economic activities. These and other religious practices of the church have been contributing to the socio economic development of the rural community in which the monastery is established.

\section{Reference}

Boender, W., Esther, Dwarswarsd, and Mariske, Westendrop. (2011). Religion and Development: practitioners' guide. Utrecht, the Netherlands.

Borowik, I., DinkaJerolimov and SinisaZrinscak. 2004. Religion and Patterns of Social Transfromation. Zagreb, Institute for Social Research.

Development and Inter- Church Aid Commission (DICAC). (2012). African Faith Commitments for a Living Planet. Ethiopian Orthodox Tewahido Church.

Kumilachew Shiferaw. (2015). The Socio Economic Role of Religion: The case of Ethiopian Orthodox Tewahido Church in Addis Ababa. Addis Ababa University, Ethiopia.

Lun2n, J. Clain. (2010). Faith in Action: Religious Organizations and Development in Kalkata, India. Royal HollowayUniversity of London.

Pesonen, H. and Vesela Kari. (2006). Congregations and Rural Development: The case of Evangelical Lutheran Church of Finland. Agricultural Economics Review, Vol.17, No.1.

Roben, R. 2011. Can Religion Contribute to Development? The road from 'Truth' to 'Trust'.Center for International Development Issues (CDIN), Rad bound University Nijmegen.

UNFPA . (2014). Religion and Development Post-2015. Report of Consultation Among Donor Organizations. UN Development Agensies and Faith-Based Organizations, New York. University Press

Wolffe, J. and Gavin Moorhead . 2015. Religion, Security and Global Uncertainties. Department of Religious Studies, The Open University, UK.

World Value Survey . 2014. Religious Communities as Partners for Development Cooperation. Federal Ministry for Economic Cooperation and Development, Germany.

Yin, K. Robert. ( 2011). Qualitative Research from Start to Finnish. The Guilford Press; A Division of Guilford Publication, Inc.

Zaidi, S. 2010. The Role of Church in the Charity and Development Sector in Karachi and Sindh, Pakistan. Religions and Development Research Programme, International Development Department, University of Birmingham. 